\section{INTERNATIONAL NEWS}

\section{News about the United European \\ Gastroenterology Federation}

\section{The UEGF in an enlarging Europe}

When the first ideas about the UEGF emerged in 1988, the Iron Curtain had only just been removed. Although there are outstanding active gastrointestinal research groups in eastern Europe, many wondered what the effects of levelling the Berlin wall and opening of the Iron Curtain on the scientific and professional developments in these countries would be. It is now clear that changes are occurring, perhaps not with lightning speed, but nevertheless they are noticeable and significant. Most remarkable in this respect is Germany. After a hesitant beginning, academics now play a leading part in dismantling the borders between East and West. For example, academic chairs in the eastern part are increasingly occupied by former West German trained professors and, as is true for many other professionals, doctors from the East have moved to the West. Similar changes are taking place in Poland, the Czech Republic, Slovakia, and Hungary where Warsaw, Prague, and Budapest, are slowly finding their place as European university towns. We are all gradually becoming better acquainted through EC sponsored exchange programmes. In addition, organisations such as the ESGE (European Society for Gastrointestinal Endoscopy), EASL (the European Association for the Study of the Liver) and others are organising courses and sponsoring meetings in eastern Europe. To reach as large a number of colleagues in eastern Europe as possible ESPGAN (European Society of Paediatric Gastroenterology and Nutrition) has taken a Travelling Summer School to tour different countries each year. The ASNEMGE (Association des Societés Nationales Européennes et Mediteranéennes de Gastroenterologie) also has longstanding ties with national organisations from the eastern part of Europe. Although for 40 years our paths have differed, the cultural heritage and the medical problems of East and West are very similar. History cannot change the facts: Semmelweis lived and worked in Budapest and Mendel in Brno; Helicobacter pylori, inflammatory bowel disease, and hepatitis $\mathrm{C}$ look very much the same whether in Poland or in Holland. It is not at all surprising that successful liver transplantation programmes have started in the Czech Republic, Slovakia, Hungary, and Poland.

What does this mean to the UEGF? We should realise that the so called seven sister societies (ASNEMGE, EAGE, ESGE, CICD, EPC, EASL, and ESPGAN), which are unified in the UEGF, all have their roots in the west. That places our colleagues from the East in a somewhat disadvantaged position. Furthermore, a true East-West balance in European gastroenterology can only be achieved from bottom up. It does not help to have executives in leading positions when the students have no chance of an academic career, a situation too well known in the East. Thus the further development of East-West student exchange programmes, clinical train- ing and research fellowships, travel grants for young investigators are all far more helpful than having someone fulfilling executive posts in any of the sister societies. However, every action in this regard does help to equalise the differences and efforts are required to ensure that exchange programmes and fellowships are adequately funded. In addition it is clear to the delegates of the UEGF council that sooner rather than later, a future UEGW should be organised in one of the great capitals of eastern Europe. Eastern European achievements have become increasingly visible in international medical conferences: for the 1995 UEGW in Berlin 2300 abstracts were submitted and 16.5 per cent came from east European countries; for this year's UEGW in Paris these figures are 2650 and 17.9 per cent. Among these, the majority come from Poland, the Czech Republic and Hungary. The number of submitted and of accepted abstracts from these countries is increasing particularly fast; this is a truly positive sign.

\section{The UEGW and the electronic revolution}

The UEGF is currently investigating the options offered by the Internet. It is clear that the annual migration of seven and in the future perhaps 10 thousand doctors may not be the most efficient means of disseminating medical knowledge. It is also bad for the environment. Teleconferencing is environmentally friendly, better for family life, less expensive, and less time consuming. It however lacks the additional cultural values that European conferences definitely have to offer. On the other hand the Internet makes many other facilities available to us, meaning big advantages for the medical profession, the first glimpses of which we are only beginning to see. Although in international football it is customary only to sell the rights to television stations after the stadiums have been sold out the UEGF will offer the entire UEGW information via $\mathrm{CD}$ ROM at the end of the conference. In addition we are developing a Web Site that will enable you to get in touch with us, in the quickest possible way. More information will be available shortly.

PETER LM JANSEN Academic Hospital Groningen, the Netherlands

PETER MILLA Institute of Child Health, London

\section{LETTERS TO THE EDITOR}

\section{Clinical ultrasound examination}

EDITOR,-I read with interest the leading article by Dr Derrick Martin (Gut 1996; 38 479-80). In Europe, clinical ultrasound, particularly of the abdomen as part of the initial patient examination, has been routine for many years. More especially, this has been performed by clinicians rather than by radiologists. The technique is easy to learn and to apply and is particularly useful when integrated into the other data available to the physician from the history taking and physical examination. Ultrasound is also useful for monitoring progress of the patient's condition, for example, the gastroenterologist will confirm or refute his ultrasound findings of the pancreaticobiliary system by ERCP, and of the intestine by endoscopy or radiology. A suggestion from the European Union of Medical Specialities through the European Board of Gastroenterology, that to obtain a European Diploma in Gastroenterology a trainee will need to undertake 300 ultrasound examinations under guidance, is a good start. It will be clear to any doctor diagnosing and treating abdominal disease, that ultrasound is an indispensable diagnostic tool. As with all techniques of course, some doctors will learn rapidly and others more slowly and perhaps some will never become real experts at the procedure and this will probably be independent of the trainee's speciality be it radiology, internal medicine, etc.

Ultrasound machines at the cheaper end of the market do not necessarily give bad results; most or at least many ultrasound diagnoses (for example, gall stones, metastatic disease, kidney tumours, etc) are reliably found with such equipment. The old adage that in driving from A to B a Rolls Royce is more comfortable but a Volkswagen will do the job as well, can certainly apply to modern ultrasound equipment now on the market.

In central Europe especially Austria, Switzerland, and Germany, abdominal ultrasound (and in addition ultrasound of the thyroid, thorax, joints, peripheral vessels, etc) is the next step after history taking and physical examination in most hospitals and also in many outpatient care institutions. By following this approach, money can be saved and many unnecessary procedures such as luminal radiology, computed tomography, etc, avoided. The procedure is time saving by excluding or proving numerous disorders and by pointing the clinician in a logical direction for further investigations, for example, ERCP. Ultrasound is quick, repeatable, and avoids radiation dosage. In my opinion and experience, at least $80 \%$ of abdominal computed tomograms can be replaced by average quality ultrasonography without compromising patient care.

Clinical ultrasound of the abdomen is also indispensable as an immediate measure in the treatment of the acute abdomen. The clinician is again involved directly in the decision making process and to this end should have easy and immediate access to perform and, if necessary, repeat ultrasound examination on such patients. In addition, it should not be forgotten that under ultrasound guidance, therapeutic procedures such as percutaneous drainage of abscesses, can be performed by clinicians directly involved in the patient's initial care and follow up.

Ultrasound training is not expensive. In the United Kingdom, courses in ultrasound training will need to be set up and departments of gastroenterology will need to consider investment in ultrasound machines. In Germany, ultrasound training courses are readily available and are usually under the aegis of departments of gastroenterology. A course of four days ( 30 hours intensive training and theory) costs about $£ 375$. In Wuppertal such courses have been offered two to four times a year since 1979 (in English since 1996). 